\title{
Epidemiological and molecular features of dengue virus type-1 in New Caledonia, South Pacific, 2001-2013
}

Myrielle Dupont-Rouzeyrol ${ }^{*}$, Maïté Aubry², Olivia O'Connor ${ }^{1}$, Claudine Roche ${ }^{2}$, Ann-Claire Gourinat ${ }^{3}$, Aurélie Guigon ${ }^{3}$, Alyssa Pyke ${ }^{4}$, Jean-Paul Grangeon ${ }^{5}$, Eric Nilles ${ }^{6}$, Suzanne Chanteau ${ }^{3}$, John Aaskov ${ }^{7}$ and Van-Mai Cao-Lormeau ${ }^{2}$

\begin{abstract}
Background: The epidemiology of dengue in the South Pacific has been characterized by transmission of a single dominant serotype for 3-5 years, with subsequent replacement by another serotype. From 2001 to 2008 only DENV-1 was reported in the Pacific. In 2008, DENV-4 emerged and quickly displaced DENV-1 in the Pacific, except in New Caledonia (NC) where DENV-1 and DENV-4 co-circulated in 2008-2009. During 2012-2013, another DENV-1 outbreak occurred in NC, the third DENV-1 outbreak in a decade. Given that dengue is a serotype-specific immunizing infection, the recurrent outbreaks of a single serotype within a 10-year period was unexpected.

Findings: This study aimed to inform this phenomenon by examining the phylogenetic characteristics of the DENV-1 viruses in NC and other Pacific islands between 2001 and 2013. As a result, we have demonstrated that NC experienced introductions of viruses from both the Pacific (genotype IV) and South-east Asia (genotype I). Moreover, whereas genotype IV and I were co-circulating at the beginning of 2012, we observed that from the second half of 2012, i.e. during the major DENV-1 outbreak, all analyzed viruses were genotype I suggesting that a genotype switch occurred.

Conclusions: Repeated outbreaks of the same dengue serotype, as observed in NC, is uncommon in the Pacific islands. Why the earlier DENV-1 outbreaks did not induce sufficient herd immunity is unclear, and likely multifactorial, but the robust vector control program may have played a role by limiting transmission and thus maintaining a large susceptible pool in the population.
\end{abstract}

Keywords: Dengue, Phylogeny, Genotype, Epidemics, New Caledonia

\section{Findings}

Dengue is the most prevalent arthropod-borne viral infection of humans in tropical and subtropical countries. Every year, dengue virus (DENV) infections cause more than 50 million cases, 500000 hospitalizations and 12500 deaths in the world [1,2]. DENV is a single-stranded, positive-sense RNA virus of the genus Flavivirus transmitted by Aedes mosquitoes. There are four distinct serotypes (DENV-1 to DENV-4) and infection with one does not provide long-term cross-protective immunity against the

\footnotetext{
* Correspondence: mdupont@pasteur.nc

'URE- Dengue et autres Arboviroses, Institut Pasteur de Nouvelle-Calédonie, Réseau International des Instituts Pasteur, 98800 Nouméa

Nouvelle-Calédonie

Full list of author information is available at the end of the article
}

three others [3,4]. Based on the sequence of the envelope gene (E), each serotype may be divided into distinct genotypes often associated with specific geographical regions. Both epidemiological observations and in vitro studies suggest that distinct genotypes have different potential to cause severe dengue epidemics [5-7]. Thus, molecular epidemiologic studies have become a critical issue for understanding epidemic patterns of viral spread.

In the Pacific, dengue epidemics were mainly caused by a single serotype/genotype introduced from a hyper-endemic continental country. In individual Pacific Islands Countries and Territories (PICTs) the epidemiology of dengue is heterogeneous. Small PICTs sustain DENV transmission for only several months, while larger ones, like French 


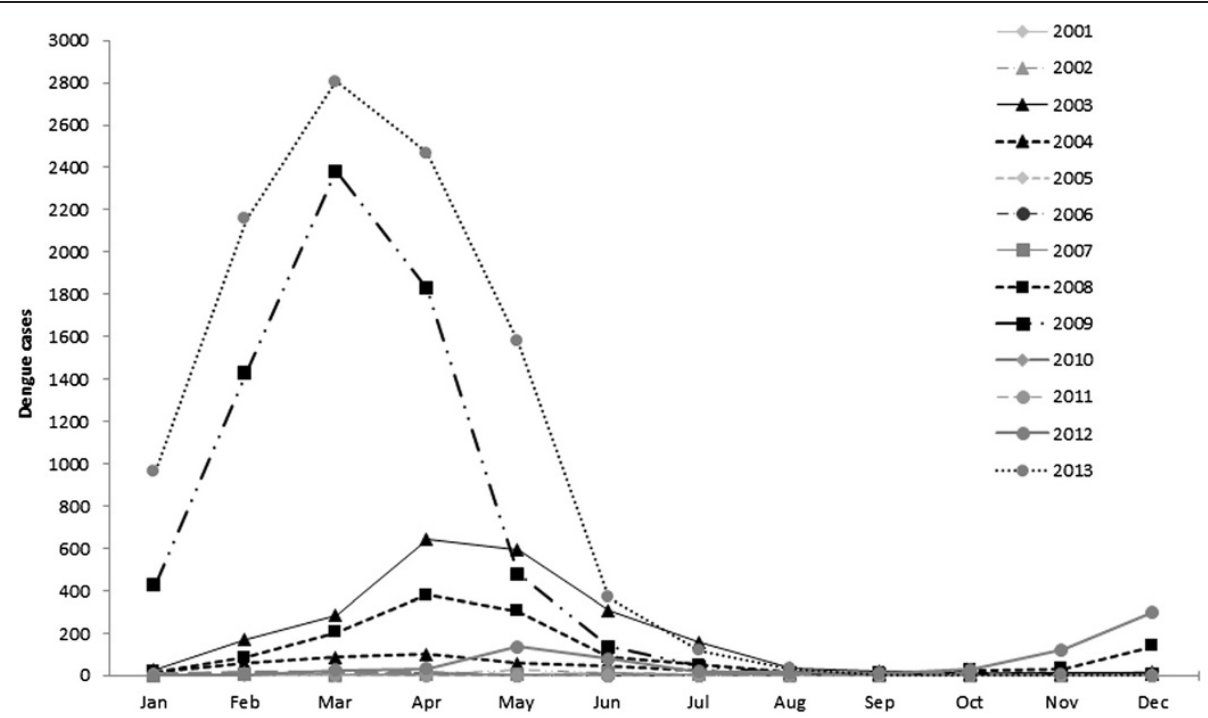

Figure 1 Dengue epidemic profile in New Caledonia from 2001 to 2013. The number of dengue cases represents the confirmed and probable cases. This Figure presents the succession of epidemic years (2003-2004, 2008-2009 and 2012-2013) and non-epidemic years in NC. It also highlights the seasonality of DENV epidemics in NC (peak in March or April).

Polynesia (PF) or New Caledonia (NC), may experience active circulation of a single serotype/genotype for several years until the emergence of a new epidemic viral strain [8-10]. In this study, we reconstruct the epidemiological and phylogenetic history of DENV-1 in $\mathrm{NC}$ during the last decade to better understand the NC dengue epidemiology.

In NC dengue epidemics have a 3-4 years cyclical pattern of occurrence [11] with dengue outbreaks usually lasting two years, with two peaks occurring during the two consecutive hot-and-rainy seasons and few cases reported during the cool season in-between (Figure 1). In
2001, as DENV-1 was emerging in several PICTs $[9,11]$, imported dengue cases from $\mathrm{PF}$ were reported in $\mathrm{NC}$. The following year, about 100 DENV-1 local cases were detected, announcing the large DENV-1 outbreak that hit the territory in 2003-2004 (Table 1) [11-13]. In 2007, after two years without any report of locally acquired DENV infections, DENV-1 cases were reported (Table 1). Half of them were imported cases from PF where a DENV-1 epidemic was still ongoing [14]. In November 2008, while DENV-1 transmission was still active, DENV4 was detected in people coming back from Vanuatu where the serotype had recently emerged $[10,15,16]$.

Table 1 New Caledonia dengue epidemiological data from the years 2001 to 2013

\begin{tabular}{|c|c|c|c|c|c|c|}
\hline Year & Diagnostic demands & Confirmed cases & Probable cases & Imported cases $^{a, b}$ & Main DENV serotype & Number of deaths ${ }^{b}$ \\
\hline 2001 & 956 & 21 & 0 & 21 & 1 & 0 \\
\hline 2002 & 1111 & 64 & 33 & 10 & 1 & 0 \\
\hline 2003 & 7758 & 601 & 1997 & nd & 1 & 17 \\
\hline 2004 & 2563 & 179 & 281 & nd & 1 & 2 \\
\hline 2005 & 760 & 2 & 43 & 2 & 1 & 0 \\
\hline 2006 & 904 & 9 & 44 & 8 & 1 & 0 \\
\hline 2007 & 1012 & 33 & 6 & 19 & 1 & 0 \\
\hline 2008 & 5262 & 1008 & 123 & 12 & 1 and 4 & 2 \\
\hline 2009 & 14927 & 6328 & 968 & 13 & 1 and 4 & 3 \\
\hline 2010 & 1841 & 25 & 67 & 1 & 1 & 0 \\
\hline 2011 & 3567 & 2 & 10 & 2 & - & 0 \\
\hline 2012 & 3986 & 654 & 54 & 3 & 1 & 1 \\
\hline 2013 & 22375 & 8545 & 1380 & 33 & 1 & 4 \\
\hline
\end{tabular}

The number of tests requests, confirmed cases (RT-PCR and/or NS1), probable cases (IgM only) and deaths probably linked to dengue are reported. amported cases among the confirmed cases, ${ }^{\mathrm{b}}$ Recorded by the Health Department of New Caledonia, $n d$ not determined. 


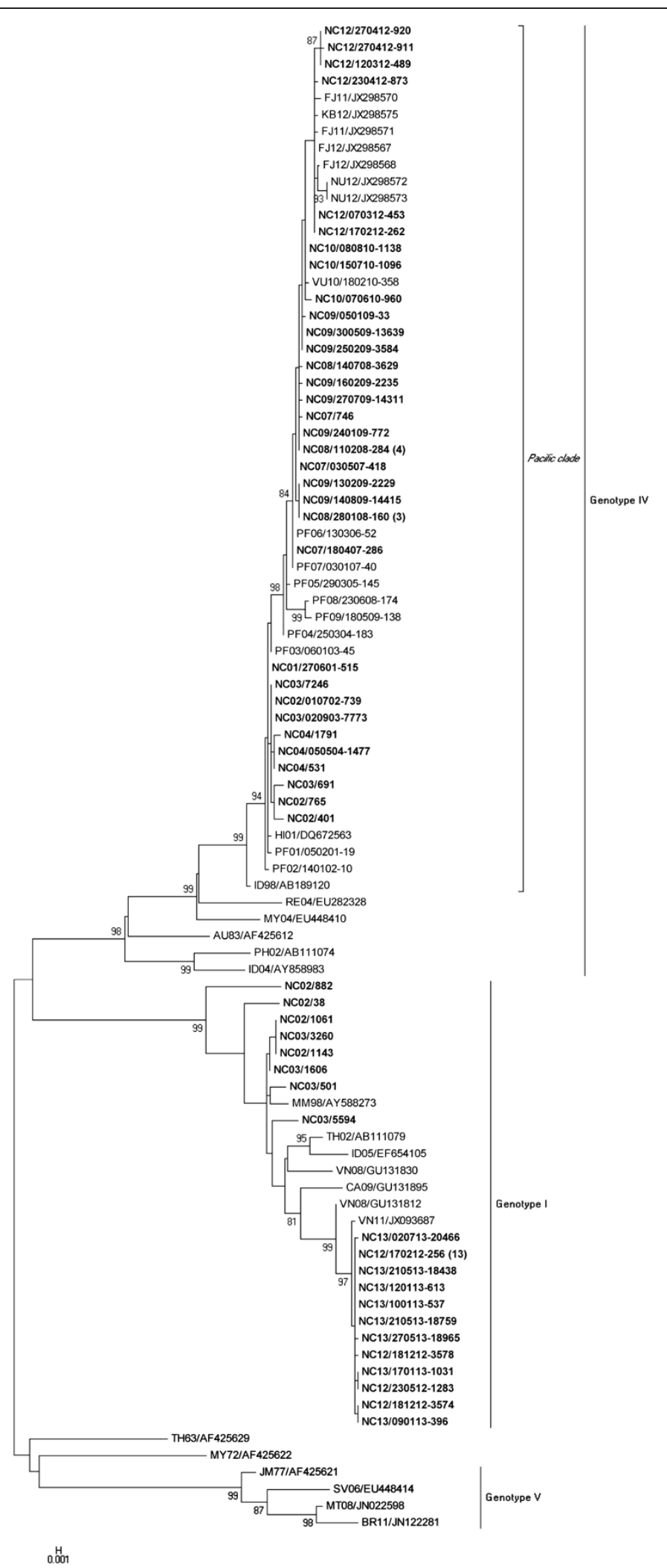

Figure $\mathbf{2}$ (See legend on next page.) 
(See figure on previous page.)

Figure 2 Evolutionary relationships of E gene sequences of DENV-1 (1478 nt). Maximum-Likelihood original trees derived from 110 DENV-1 E gene sequences ( 90 PICTs and 20 retrieved from GenBank). The percentage of replicate trees in which the associated taxa clustered together in the bootstrap test (1000 replicates) is shown for values over 80 . The period (years) these strains have been collected is indicated just after the country isocode. The number in brackets represents the number of NC DENV-1 strains identical (nucleotide sequence) to the strain reported on the tree. The $73(53+20$ in brackets) NC DENV-1 strains are shown in bold. Genbank accession numbers of the DENV-1 E gene sequenced for this study are reported in Additional file 1.

These were the first DENV-4 cases reported in NC for more than 25 years [17]. Despite an active surveillance, NC health authorities did not reach to prevent and control the introduction of DENV-4. In 2009, NC experienced an epidemic concomitantly involving DENV-1 and DENV-4 (Table 1) [13]. In 2010, no more DENV-4 cases were reported while DENV-1 continued to be detected until the end of year. The serotype switch observed in other PICTs did not occur in NC $[10,16]$. In 2011, no dengue cases were detected although the number of dengue suspected cases had dramatically increased due to the occurrence of the first chikungunya epidemic ever reported in NC $[18,19]$. Unexpectedly, DENV-1 re-emerged in 2012-2013 in $\mathrm{NC}$ and caused the largest outbreak ever reported (Figure 1 and Table 1) [13]. This outbreak was particularly severe: rapid increase of the number of cases, high rate of hospitalization in a short time, important transmission during the cool season, restart of active transmission early after the cool season.

In this study, envelope (E) genes from 90 DENV-1 viruses recovered in NC and other PICTs (Additional file 1) were amplified by RT-PCR and sequenced as described previously [16]. As DENV-1 is divided in five genotypes [5], manually designed oligonucleotide primers D1M/869F (5'-GGAACATCCATCACCCAGAA-3') and D1NS1/2510R (5'-CTCTGTCCAGGTGTGAACTT-3') were used for both amplification and sequencing of genotype IV viruses, additional primers D1E/1352F (5'-GTGATCGTTACTGTCCA $\left.C A C-3^{\prime}\right)$ and D1E/OOCF (5'- GTAATAGTCACCGTCCA $\left.C A C-3^{\prime}\right)$ were used to sequence genotype IV and I viruses respectively. Overlapping fragments were assembled with Staden Package (MRC Cambridge, England). Nucleotide sequences were aligned with the multiple sequence alignment software Clustal W integrated in MEGA version 5.0 software. Phylogenetic analysis was then carried out with MEGA5, using the Maximum likelihood method. The evolutionary distances were computed using the Kimura 2-parameter method defined as one of the best evolution model with MEGA5. As shown by the Figure 2, NC strains collected from 2001 to 2013 belong to genotypes I and IV. All sequenced genotype IV viruses recovered in NC during the last decade group together with other DENV-1 strains collected in PICTs during the same period within the "Pacific clade" previously described [9]. DENV-1/genotype IV viruses recovered in NC from 2002 to 2004 and from 2007 to 2012 are close to strains isolated in PF in 2001-2002 and in 2006-2007 respectively. This observation corroborates epidemiological data that suggested that the first two dengue outbreaks of the decade in NC resulted from introduction of DENV-1 viruses from PF. Interestingly, NC genotype IV viruses recovered in 2012 are closely related to DENV-1 strains collected in Fiji, Kiribati and Niue within the same year. Based on our findings, the re-emergence of DENV-1 genotype IV in NC in 2012 may have resulted from introductions of viruses from other PICTs. Genotype I viruses recovered in NC form two clearly independent clusters, the first cluster includes strains collected in 2002-2003 as mentioned before $[8,20]$, the second cluster contains viruses isolated in NC in 2012-2013. This later cluster is close to a strain recovered in Vietnam in 2011 (VN11/JXD93687) what suggests that the re-emergence of DENV-1 genotype I in NC in 2012 resulted from a new introduction of a virus from South-east Asia. Moreover, the amino acids analysis showed that all NC 2012-2013 DENV-1/genotype I strains share 100\% homology with the VN11/JXD93687 and VN08/GU131812 strains (data not shown). From February to July 2012, DENV-1 viruses recovered in NC belonged to either genotype I or IV. From August 2012 to the end of 2013, all the NC DENV-1 strains sequenced were genotype I (Figure 2). Moreover all DENV-1 positive sera collected in August 2012 and in August 2013 were all amplified by genotype I specific RT-PCR using the primers D1E/MDRF (5'- GAAATATTCAGTAATAGTCA CCGT-3') and D1EREV-R (5'- CATGGTGCATCTGTT $\left.C C-3^{\prime}\right)$ (data not shown). These data are suggesting that a switch occurred in the genotype circulating as observed in hyperendemic countries [21].

The occurrence of two consecutive outbreaks due to the same dengue serotype had historically already been observed in NC and other PICTs [7,11]. Thus, the reemergence of DENV-1 in NC in 2008, i.e. five years after the previous DENV-1 outbreak, was not surprising, particularly given the active circulation of the virus in PF. However, what was unexpected was the fact that DENV-1 was not replaced by DENV-4 during the 2008-2009 outbreak and that both serotype circulated during more than a year. The absence of serotype replacement contrasts with the historical data on the epidemiology of dengue in PICTs and with the situation reported during the same period in other PICTs $[10,15]$. Otherwise in contrast with the NC historical dengue epidemiological profile [11] 
DENV-1 re-emerged in NC in 2012 although this serotype had already circulated in the country for ten years. As suggested by our phylogenetic analyses the recurrent re-emergences of DENV-1 over the last decade in NC mainly resulted from introductions of "Pacific clade" genotype IV viruses from other PICTs, particularly PF. In addition introduction of South-east Asian genotype I viruses also contributed to the circulation of DENV-1 in NC, at least transiently in 2002-2003 [8,20] and sustainably in 2012-2013. The fact that introductions events led to sustainable circulation of DENV-1 and the occurrence of three consecutive outbreaks suggests that, at least until 2013, the NC population did not already had acquired sufficient herd immunity against DENV-1. The observation that NC experienced strong positive human migratory threshold during the past 5 years suggest that the pool of susceptible hosts may have been resupplied by new residents [22]. Another factor that could have contributed to maintain the pool of susceptible hosts is the limitation of DENV-1 infection rates during the 2008-2009 outbreak, due to transient cross-protective immunity provided by the co-circulation of DENV-4 [23]. An alternative factor that might have contributed to maintain the proportion of susceptible hosts to a level compatible with sustained DENV-1 transmission is the vector control pressure. For several years, NC Health Authorities have invested lots of efforts in maintaining efficient vector control. Combined to the NC standard of living (air conditioning...) and to climate conditions less favorable to DENV transmission during the cool season, vector control measures might have contributed to modify dengue epidemiological profile. An additional factor that could have contributed to sustainable transmission of DENV-1 in NC in 2012-2013 is the emergence of Asian genotype I. Indeed, this is the first evidence of a genotype switch (Pacific to Asian) in NC and in the Pacific region. This observation supports the hypothesis that transmission of Asian genotype I was particularly efficient in the context of NC in 2012-2013. Indeed it has been shown that genotype switch can favour the persistence of a serotype in a specific environment and that distinct genotypes can display different epidemic potential $[6,7,24,25]$. Finally, what has been observed in NC might be the beginning of a new situation regarding the dengue circulation profile in the Pacific.

\section{Additional file}

Additional file 1: List of the PICTs DENV-1 strains analyzed in this study.

\section{Competing interests}

The authors declare that they have no competing interests.

\section{Authors' contributions}

MDR designed the experiments, performed the molecular experiments, analyzed the data and drafted the manuscript. VMCL conceived the study, designed the experiments and drafted the manuscript. MA designed the experiments, performed the molecular experiments and analyzed the data. OOC performed the molecular experiments and analyzed the data. CR analyzed the data. ACG and AG carried out the clinical diagnosis. JA, JPG and AP contributed to materials and data analysis and revised the manuscript. EN and SC critically revised the manuscript for intellectual content. All authors read and approved the final manuscript.

\section{Acknowledgments}

We are grateful to M. Kama (Fiji), M. Nosa (Niue) and K. Tabutoa (Kiribati) for releasing access to their DENV sequences. We thank E. Calvez and A. Rouby for participating in the sequences analysis, L. Guillaumot, S. Mermond and D. Baudon for scientific support and the Immuno-Molecular biology lab from Institut Pasteur New Caledonia. Part of the sequencing experiments were performed on « La Plateforme du Vivant », Noumea, New Caledonia. This work was supported by the "Fonds de Coopération Economique, Sociale et Culturelle pour le Pacifique", Ministère des Affaires Etrangères et Européennes, France (Conventions Nu138/1/2008, 75/1/2009); by the "Agence Nationale pour la Recherche", France (ANR-09-MIEN-028-01/02) and the New Caledonia Government. The funders had no role in study design, data collection and analysis, decision to publish, or preparation of the manuscript.

\section{Author details}

'URE- Dengue et autres Arboviroses, Institut Pasteur de Nouvelle-Calédonie, Réseau International des Instituts Pasteur, 98800 Nouméa,

Nouvelle-Calédonie. ${ }^{2}$ Institut Louis Malardé, 98713 Papeete Tahiti, Polynésie Française. ${ }^{3}$ Institut Pasteur de Nouvelle-Calédonie, Réseau International des Instituts Pasteur, 98800 Nouméa, Nouvelle-Calédonie. ${ }^{4}$ Queensland Health Forensic and Scientific Services, QLD 4108 Coopers Plains, Australia. ${ }^{5}$ Direction des Affaires Sanitaires et Sociales, 98800 Nouméa, Nouvelle-Calédonie. ${ }^{6}$ Pacific Technical Support Division, World Health Organization, PO BOX 113, Suva, Fiji. ' Queensland University of Technology, Brisbane QLD 4001, Australia.

Received: 24 October 2013 Accepted: 27 March 2014 Published: 31 March 2014

\section{References}

1. Guzman MG, Kouri G: Dengue: an update. Lancet Infect Dis 2002, 2:33-42.

2. World Health Organisation: Dengue Guidelines for Diagnosis, Treatment, Prevention and Control. Geneva: TDR/WHO; 2009. Available: http://whalibdoc.who.int/publications/2009/9789241547871_eng.pdf.

3. Sabin AB: Research on dengue during World War II. Am J Trop Med Hyg 1952, 1:30-50.

4. Calisher CH, Karabatsos N, Dalrymple JM, Shope RE, Porterfield JS, Westaway $E G$, Brandt WE: Antigenic relationships between flaviviruses as determined by cross-neutralization tests with polyclonal antisera. J Gen Virol 1989, 70(Pt 1):37-43.

5. Rico-Hesse R: Microevolution and virulence of dengue viruses. Adv Virus Res 2003, 59:315-341.

6. Vu TT, Holmes EC, Duong V, Nguyen TQ, Tran TH, Quail M, Churcher $C$ Parkhill J, Cardosa J, Farrar J, Wills B, Lennon NJ, Birren BW, Buchy P, Henn MR, Simmons CP: Emergence of the Asian 1 genotype of dengue virus serotype 2 in viet nam: in vivo fitness advantage and lineage replacement in South-East Asia. PLoS Negl Trop Dis 2010, 4:e757.

7. Lambrechts L, Fansiri T, Pongsiri A, Thaisomboonsuk B, Klungthong C, Richardson JH, Ponlawat A, Jarman RG, Scott TW: Dengue-1 virus clade replacement in Thailand associated with enhanced mosquito transmission. J Virol 2012, 86:1853-1861.

8. A-Nuegoonpipat A, Berlioz-Arthaud A, Chow V, Endy T, Lowry K, le Mai Q, Ninh TU, Pyke A, Reid M, Reynes JM, Su Yun ST, Thu HM, Wong SS, Holmes EC, Aaskov J: Sustained transmission of dengue virus type 1 in the Pacific due to repeated introductions of different Asian strains. Virology 2004, 329:505-512.

9. Descloux E, Cao-Lormeau VM, Roche C, De Lamballerie X: Dengue 1 diversity and microevolution, French Polynesia 2001-2006: connection with epidemiology and clinics. PLoS Negl Trop Dis 2009, 3:e493. 
10. Li DS, Liu W, Guigon A, Mostyn C, Grant R, Aaskov J: Rapid displacement of dengue virus type 1 by type 4, Pacific region, 2007-2009. Emerg Infect Dis 2010, 16:123-125.

11. Singh N, Kiedrzynski T, Lepers C, Benyon EK: Dengue in the Pacific-an update of the current situation. Pac Health Dialog 2005, 12:111-119.

12. Bouldouyre MA, Baumann F, Berlioz-Arthaud A, Chungue E, Lacassin F: Factors of severity at admission during an epidemic of dengue 1 in New Caledonia (South Pacific) in 2003. Scand J Infect Dis 2006, 38:675-681.

13. Situation Sanitaire de Nouvelle-Calédonie. La Dengue. Rapport des années précédentes. http://www.dass.gouv.nc/portal/page/portal/dass/ observatoire_sante/situation_sanitaire/rapports_annees_precedentes.

14. Daudens E, Lastere S, Hirschauer C, Cao-Lormeau VM, Louette R, Roche C, Chee-Ayee A, Goffard N, Vrousos E, Renou L, Wiegandt A, Mallet HP: Epidemiology of dengue and control strategies in French Polynesia from 2006 to 2008. Bull Epidémiol Hebd 2009, 48-49-50:499-502.

15. Cao-Lormeau VM, Roche C, Aubry M, Teissier A, Lastere S, Daudens E, Mallet HP, Musso D, Aaskov J: Recent emergence of dengue virus serotype 4 in French polynesia results from multiple introductions from other South pacific islands. PLoS One 2011, 6:e29555.

16. Aubry M, Roche C, Dupont-Rouzeyrol M, Aaskov J, Viallon J, Marfel M, Lalita P, Elbourne-Duituturaga S, Chanteau S, Musso D, Pavlin BI, Harrison D, Kool JL, Cao-Lormeau VM: Use of serum and blood samples on filter paper to improve the surveillance of dengue in Pacific Island Countries. J Clin Virol 2012, 55:23-29.

17. Chungue E, Cassar O, Drouet MT, Guzman MG, Laille M, Rosen L, Deubel V: Molecular epidemiology of dengue- 1 and dengue-4 viruses. J Gen Virol 1995, 76(Pt 7):1877-1884.

18. Alibert A, Pfannstiel A, Grangeon J: Chikungunya outbreak in New Caledonia in 2011 Status report as at 22 August 2011. Inform'Action 2011, 34:3-9.

19. Dupont-Rouzeyrol M, Caro V, Guillaumot L, Vazeille M, D'Ortenzio E, Thiberge JM, Baroux N, Gourinat AC, Grandadam M, Failloux AB: Chikungunya virus and the mosquito vector Aedes aegypti in New Caledonia (South Pacific Region). Vector Borne Zoonotic Dis 2012 12:1036-1041.

20. Aaskov J, Buzacott K, Field E, Lowry K, Berlioz-Arthaud A, Holmes EC: Multiple recombinant dengue type 1 viruses in an isolate from a dengue patient. J Gen Virol 2007, 88:3334-3340.

21. Yamanaka A, Mulyatno KC, Susilowati H, Hendrianto E, Ginting AP, Sary DD, Rantam FA, Soegijanto S, Konishi E: Displacement of the predominant dengue virus from type 2 to type 1 with a subsequent genotype shift from IV to I in Surabaya, Indonesia 2008-2010. PLoS One 2011, 6:e27322.

22. Rivoilan P, Broustet D: Recensement de la population en NouvelleCalédonie en 2009. INSEE Première 2011, 1138:1-4

23. Reich NG, Shrestha S, King AA, Rohani P, Lessler J, Kalayanarooj S, Yoon IK, Gibbons RV, Burke DS, Cummings DA: Interactions between serotypes of dengue highlight epidemiological impact of cross-immunity. J $R$ Soc Interface 2013, 10:20130414.

24. Teoh BT, Sam SS, Tan KK, Johari J, Shu MH, Danlami MB, Abd-Jamil J, MatRahim N, Mahadi NM, AbuBakar S: Dengue virus type 1 clade replacement in recurring homotypic outbreaks. BMC Evol Biol 2013, 13:213.

25. Lourenco J, Recker M: Viral and epidemiological determinants of the invasion dynamics of novel dengue genotypes. PLoS Negl Trop Dis 2010, 4:e894.

doi:10.1186/1743-422X-11-61

Cite this article as: Dupont-Rouzeyrol et al: Epidemiological and molecular features of dengue virus type- 1 in New Caledonia, South Pacific, 2001-2013. Virology Journal 2014 11:61.

\section{Submit your next manuscript to BioMed Central and take full advantage of:}

- Convenient online submission

- Thorough peer review

- No space constraints or color figure charges

- Immediate publication on acceptance

- Inclusion in PubMed, CAS, Scopus and Google Scholar

- Research which is freely available for redistribution

Submit your manuscript at www.biomedcentral.com/submit 